\title{
Middlebrook 7H9 Growth Medium
}

National Cancer Institute

\section{Source}

National Cancer Institute. Middlebrook 7H9 Growth Medium. NCI Thesaurus. Code C127521.

A liquid growth medium developed specifically for the primary and secondary cultivation of mycobacterium, which comprises albumin, glycerol, dextrose, and inorganic compounds. 